\title{
Regional anesthesia in Marfan syndrome, not all dural ectasias are the same: a report of two cases
}

\section{Anesthésie régionale dans le syndrome de Marfan; toutes les ectasies de la dure-mère ne se ressemblent pas : une étude de deux cas}

\author{
Leyla Baghirzada, MD • Timo Krings, MD, PhD • \\ Jose C. A. Carvalho, MD, PhD \\ Received: 20 July 2012/Accepted: 21 August 2012/Published online: 14 September 2012 \\ (C) Canadian Anesthesiologists' Society 2012
}

\begin{abstract}
Background The anesthetic management of women with Marfan syndrome and dural ectasia undergoing Cesarean delivery remains controversial. We present two cases of patients with Marfan syndrome and dural ectasia where neuraxial anesthesia was used successfully.

Case 1 A 31-yr-old G1P0 female with Marfan syndrome presented for elective Cesarean delivery at $35^{3 / 7}$ weeks' gestation. The magnetic resonance imaging of her spine revealed significant dural ectasia in the lumbosacral area with a mean lumbar dural sac area of $4.71 \mathrm{~cm}^{2}$. Intrathecal administration of $0.75 \%$ hyperbaric bupivacaine $9 \mathrm{mg}$ produced only limited perineal analgesia. The epidural catheter was titrated, and $0.5 \%$ bupivacaine $150 \mathrm{mg}$ were required to achieve a T4 sensory level.
\end{abstract}

Case 2 A 34-yr-old G1P0 female with Marfan syndrome presented for elective Cesarean delivery at 37 weeks' gestation. The intrathecal administration of $0.75 \%$

Author contributions Leyla Baghirzada and Jose C.A. Carvalho cared for patients, reviewed the literature, and wrote the manuscript. Jose C.A. Carvalho and Timo Krings revised the manuscript, and Leyla Baghirzada submitted the final version of the manuscript. Timo Krings interpreted the magnetic resonance imagings for both patients.

L. Baghirzada, MD · J. C. A. Carvalho, $\mathrm{MD}, \mathrm{PhD}$

Department of Anesthesia and Pain Management, Mount Sinai

Hospital, University of Toronto, Toronto, ON, Canada

T. Krings, MD, PhD

Division of Neuroradiology, Toronto Western Hospital,

University of Toronto, Toronto, ON, Canada

L. Baghirzada, MD ( $\square)$

Department of Anesthesia, Foothills Medical Center, C-229,

1403 29th St. N.W., Calgary, AB T2N 2T9, Canada

e-mail: leylashka@yahoo.com hyperbaric bupivacaine $13.5 \mathrm{mg}$ produced a T5 sensory level. Magnetic resonance imaging of her spine prior to discharge confirmed the diagnosis of moderate dural ectasia with a mean lumbar dural sac area of $3.61 \mathrm{~cm}^{2}$.

Discussion The two patients described in this report responded differently to spinal anesthesia, most likely based on the severity of their dural ectasia. Although preoperative magnetic resonance imaging may help to identify patients at risk for a failed spinal, we suggest considering a combined spinal-epidural technique in cases of dural ectasia.

\section{Résumé}

Contexte La prise en charge anesthésique de femmes ayant un syndrome de Marfan et une ectasie de la dure-mère au cours d'un accouchement par césarienne reste un sujet controversé. Nous présentons le cas de deux patientes ayant un syndrome de Marfan et une ectasie de la dure-mère chez qui une anesthésie neuraxiale a été réalisée avec succès.

Cas $\mathbf{n}^{\circ} 1$ Une femme de 31 ans, G1P0, ayant un syndrome de Marfan a été admise pour accouchement par césarienne programmé à 35 semaines et 3 jours de grossesse. L'imagerie par résonance magnétique de la colonne vertébrale a révelé une ectasie significative de la dure-mère dans la région lombosacrée avec une surface moyenne du sac dural lombaire de 4,71 $\mathrm{cm}^{2}$. L'administration intrathécale de $9 \mathrm{mg}$ de bupivacaïne hyperbare à $0,75 \%$ n'a procuréqu'une analgésie périnéale limitée. La dose du cathéter péridural a été titrée et $150 \mathrm{mg}$ de bupivacaïne 0,5\% ont éténécessaires pour atteindre le niveau sensitif $D 4$.

Cas $\mathbf{n}^{\circ} 2$ Une femme de 34 ans, G1P0, ayant un syndrome de Marfan a été admise pour accouchement par césarienne programmé à 37 semaines de grossesse. L'administration intrathécale de 13,5 mg de bupivacaïne 
hyperbare à $0,75 \%$ a permis d'atteindre le niveau sensitif D5. Une IRM de la colonne vertébrale, effectuée avant le congé de la patiente a confirmé le diagnostic d'ectasie modérée de la dure-mère, avec une surface moyenne du sac dural lombaire de 3,61 $\mathrm{cm}^{2}$.

Discussion Les deux patientes décrites dans cet article ont répondu différemment à la rachianesthésie, le plus probablement en rapport avec la gravitéde leur ectasie durale. Bien que l'imagerie par résonance magnétique préopératoire puisse aider à identifier les patientes à risque d'échec de la rachianesthésie, nous suggérons qu'une technique combinée de rachianesthésie et d'anesthésie péridurale soit envisagée dans les cas d'ectasie de la dure-mère.

Marfan syndrome is an autosomal dominant connective tissue disorder with a reported incidence of one in 3,000-5,000 individuals. ${ }^{1}$ It is caused by mutation in the fibrillin- 1 gene located on chromosome 15 . $^{2}$ The cardinal features occur in the skeletal, ocular, and cardiovascular systems, but other organs can also be affected, including the skin, lungs, and dura.

The most important complication of Marfan syndrome is the progressive dilatation of the aortic root and ascending aorta, leading to aortic valve incompetence and aortic dissection. ${ }^{3}$ Another major feature in the diagnostic criteria $^{4}$ is dural ectasia (DE), defined as the widening of the spinal canal, indentation of the vertebral body posteriorly, thinning of the cortex and laminae as a result of longstanding pressure, widening of the neural foraminae, or presence of meningocele. ${ }^{5}$ The prevalence of DE in patients with Marfan syndrome is estimated to be from 63-92\%. ${ }^{6}$ Although DE can occur at different levels of the lumbar spine, it is most common at the L5-S1 level. ${ }^{7}$

The anesthetic management of these patients can be challenging, and the literature regarding the management of these cases is scarce. Spinal anesthesia may result in undesirable hemodynamic changes in patients with significant cardiovascular disease and may fail as a result of an increased volume of lumbar cerebrospinal fluid (CSF). ${ }^{8}$ While epidural anesthesia provides more stable hemodynamics, it may be difficult to perform due to scoliosis, and it has been associated with failure. ${ }^{1,9}$

We present two cases of patients with Marfan syndrome and associated DE. Both patients presented for elective Cesarean delivery where neuraxial anesthesia was used successfully but performed very differently. Both patients gave written informed consent for publication of this information.

\section{Case 1}

A 31-yr-old G1P0 female with clinical features suggestive of Marfan syndrome was referred for anesthesia consult at
34 weeks' gestation in anticipation of an upcoming Cesarean delivery. The diagnosis of Marfan syndrome was not confirmed by genetic testing; however, she had a typical body habitus: height $178 \mathrm{~cm}$, weight $98 \mathrm{~kg}$, and arachnodactyly. The echocardiogram prior to conception showed mild global left ventricular hypokinesia, bicuspid aortic valve with mild aortic regurgitation, mitral valve prolapse, and a dilated aortic root measuring $42 \mathrm{~mm}$. The aortic root was assessed by cardiac magnetic resonance imaging (MRI) during the patient's pregnancy; it increased gradually and measured $48 \mathrm{~mm}$ at 32 weeks' gestation. Beta-blocker therapy was initiated for heart rate and blood pressure control. A spine image obtained as part of the cardiac MRI revealed the presence of DE involving the lumbosacral spine and extending into bilateral perineural cysts within the sacrum (Fig. 1). The anteroposterior diameter of the lumbar dural sac ranged from $1.8-2.2 \mathrm{~cm}$ with a mean lumbar dural sac area of $4.71 \mathrm{~cm}^{2}$ (Table 1). There was a mild cervicothoracic scoliosis. Due to progressive dilatation of the aortic root, a Cesarean delivery was planned at $35^{3 / 7}$ weeks' gestation. The patient remained asymptomatic throughout her pregnancy and continued to belong to New York Heart Association (NYHA) Class I at the time of the Cesarean delivery. The Cesarean delivery was performed under a double-segment combined spinal-epidural (CSE) anesthetic. The patient was monitored with a noninvasive blood pressure cuff on each arm, five-lead electrocardiogram, pulse oximeter, and noninvasive cardiac output monitor $\left(\mathrm{NICOM}^{\mathrm{TM}}\right.$ Cheetah Medical Inc, Portland, OR, USA). Pre-procedural ultrasound scanning of the patient's spine was performed, and the appropriate intervertebral spaces were identified. With the patient in the sitting position, an end-hole epidural catheter (Arrow FlexTip Plus ${ }^{\circledR}$ ) was placed at the L3-4 interspace without any difficulty, and an electrical stimulation test ${ }^{10}$ was used to confirm its position. The spinal component of the CSE was introduced at the L4-5 interspace. We used $0.75 \%$ hyperbaric bupivacaine $9 \mathrm{mg}$, fentanyl $10 \mu \mathrm{g}$, and preservative-free morphine $100 \mu \mathrm{g}$. Fifteen minutes following the intrathecal injection, the patient had only limited perineal analgesia as assessed by pinprick sensation using a blunt $25 \mathrm{G}$ needle and cold sensation to ice. The epidural injection was carefully titrated over the next $15 \mathrm{~min}$, and $30 \mathrm{~mL}$ of $0.5 \%$ isobaric bupivacaine were required to achieve a bilateral $\mathrm{T} 4$ sensory level. Baseline systolic blood pressure levels were maintained with phenylephrine boluses given in increments of $0.1 \mathrm{mg} i v$ as required.

The remainder of the procedure was uneventful, and the patient delivered a live male infant with Apgar scores 9 and 9 at one and five minutes, respectively. Additional preservative-free morphine $2.5 \mathrm{mg}$ was injected through the epidural catheter for postoperative pain control. The patient 
Fig. 1 Case 1: (A) Sagittal view of the spine on a $\mathrm{T} 2$ weighted fat suppressed image demonstrating the widened spinal canal that is more pronounced in the lower thoracic and lumbar regions below the conus medullaris. (B) Axial cut at the L2 level on a T2 weighted scan with measurements of the width of the spinal canal in transverse and antero-posterior dimensions demonstrating widening of the spinal canal

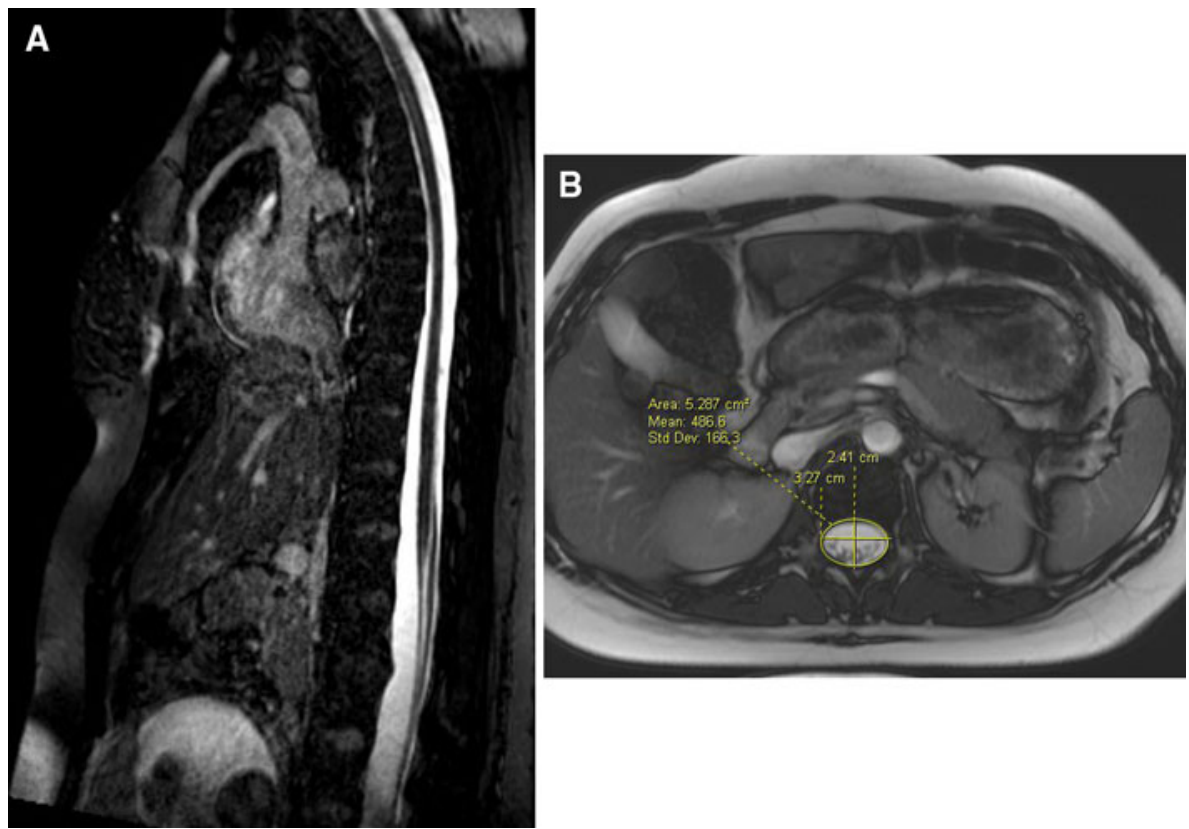

Table 1 Dural sac dimensions by magnetic resonance imaging at L1-L5 levels

\begin{tabular}{|c|c|c|c|c|c|c|c|}
\hline \multirow[t]{2}{*}{ Level } & \multicolumn{3}{|l|}{ Case 1} & \multicolumn{3}{|c|}{ Case 2} & \multirow{2}{*}{$\begin{array}{l}\text { Reference values }^{15} \\
\text { Anteroposterior diameter }(\mathrm{cm}) \text { with } \\
95 \% \text { confidence interval ( ) }\end{array}$} \\
\hline & $\begin{array}{l}\text { Area } \\
\left(\mathrm{cm}^{2}\right)\end{array}$ & $\begin{array}{l}\text { Antero-posterior } \\
\text { diameter }(\mathrm{cm})\end{array}$ & $\begin{array}{l}\text { Mediolateral } \\
\text { diameter }(\mathrm{cm})\end{array}$ & $\begin{array}{l}\text { Area } \\
\left(\mathrm{cm}^{2}\right)\end{array}$ & $\begin{array}{l}\text { Antero-posterior } \\
\text { diameter }(\mathrm{cm})\end{array}$ & $\begin{array}{l}\text { Mediolateral } \\
\text { diameter }(\mathrm{cm})\end{array}$ & \\
\hline L1 & 3.30 & 1.8 & 2.6 & 2.75 & 1.6 & 2.5 & $1.4(1.2$ to 1.7$)$ \\
\hline L2 & 5.28 & 2.4 & 3.3 & 3.32 & 1.9 & 2.4 & $1.3(1.0$ to 1.6$)$ \\
\hline L3 & 4.83 & 2.2 & 2.6 & 3.26 & 1.6 & 2.2 & $1.3(0.8$ to 1.6$)$ \\
\hline L4 & 4.95 & 2.2 & 3.3 & 4.45 & 2.2 & 2.7 & $1.2(0.7$ to 1.6$)$ \\
\hline L5 & 5.18 & 2.2 & 3.2 & 4.28 & 2.0 & 3.0 & $1.1(0.6$ to 1.6$)$ \\
\hline
\end{tabular}

was monitored on the labour and delivery floor for $24 \mathrm{hr}$ and then transferred to the ward. On the fifth postoperative day, she underwent surgery for aortic root repair and was discharged home 12 days later.

\section{Case 2}

A 34-yr-old G1P0 female with a known diagnosis of Marfan's syndrome was referred for anesthesia consultation at $34^{2 / 7}$ weeks' gestation. She had a typical body habitus (height $185 \mathrm{~cm}$, weight $56 \mathrm{~kg}$ ) and a family history of "Marfanoid" phenotype. The patient had known progressive aortic root dilatation over the last six years; however, it was stable throughout her pregnancy and measured $45 \mathrm{~mm}$. Beta-blocker therapy was maintained throughout her pregnancy. She was asymptomatic and continued to belong to NYHA Class I, and there was no spine imaging to confirm the presence of DE. Cesarean delivery at 37 weeks' gestation was planned. Ultrasound scanning was performed prior to neuraxial anesthesia to identify the appropriate intervertebral space, and the patient was monitored with standard monitors as well as with NICOM. A two-segment CSE was planned. With the patient in the sitting position, the epidural catheter was inserted at the L2-3 level without any difficulty, and the correct position was confirmed with electric stimulation. The spinal anesthetic was injected at the L3-4 level and consisted of $0.75 \%$ hyperbaric bupivacaine $13.5 \mathrm{mg}$, fentanyl $10 \mu \mathrm{g}$, and preservative-free morphine $100 \mu \mathrm{g}$ as per our standard practice. Fifteen minutes following the injection, a bilateral T5 sensory level was obtained. Surgery was uneventful, and the patient delivered a female infant with Apgar scores 9 and 9 at one and five minutes, respectively. The epidural catheter was not used for supplementary anesthesia during the surgery. The patient was monitored on the labour and delivery unit for $24 \mathrm{~h}$ and later transferred to the ward. She was discharged home on the fourth postoperative day without any complications. Prior to discharge, she underwent a spinal MRI, and the diagnosis of DE was confirmed (Fig. 2). The anteroposterior diameter of the lumbar dural sac ranged from $1.6-2.0 \mathrm{~cm}$, with a mean lumbar dural sac area of $3.61 \mathrm{~cm}^{2}$ (Table 1). 
Fig. 2 Case 2: (A) Sagittal T2 Turbo spin echo sequence of the lumbar spine demonstrating significant dural ectasias with scalloping of the vertebral bodies of the entire lumbar spine and significant dilatation of the spinal canal. (B) Axial cut at the $\mathrm{L} 2$ level on a $\mathrm{T} 1$ weighted scan with measurements of the width of the spinal canal in transverse and antero-posterior dimensions demonstrating widening of the spinal canal. Note also the thinned pedicles as a typical finding in Marfan syndrome

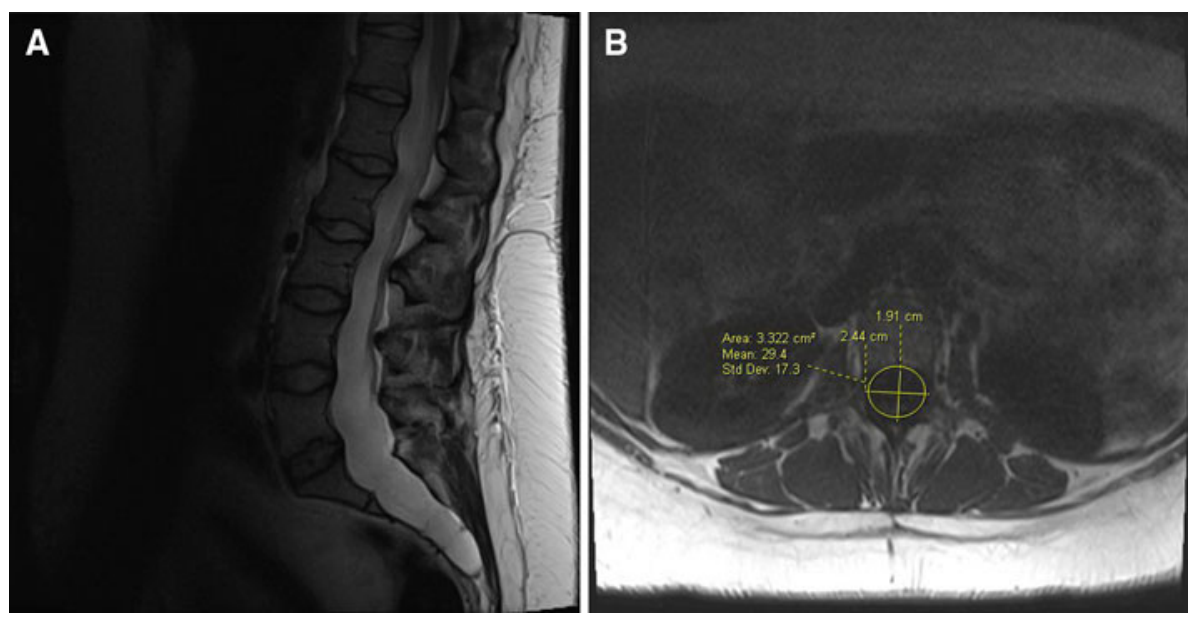

\section{Discussion}

Our results confirm the successful use of neuraxial anesthesia in Marfan patients with DE; however, our results also suggest that the degree of DE may limit the efficacy of spinal anesthesia and require the use of epidural anesthesia.

The etiology of DE is unclear. The predominant presence of DE at the lowest vertebra supports the theory that the development of ectasia is influenced by hydrostatic pressure on a weakened dura. ${ }^{11}$ Patients are usually asymptomatic, but some may develop lower back pain, headache, proximal leg pain, weakness and numbness above and below the knee, and genital/rectal pain. ${ }^{7}$ Dural ectasia has also been reported in patients with neurofibromatosis type 1, Ehler-Danlos syndrome, ankylosing spondylitis, trauma, tumours, and scoliosis. ${ }^{12-14}$

The severity of DE can be evaluated by computed tomography or MRI using either quantitative (actual dural sac measurements) or qualitative (evaluating the prevalence of different features of DE, i.e., scalloping) criteria. There are no universally accepted quantitative criteria for diagnosing DE, and various methods have been used, including evaluation of dural sac ratio, ${ }^{15}$ assessment of dural sac diameter at S1 and L4 levels, nerve root sleeve diameter, ${ }^{16}$ and lumbar pedicle width. ${ }^{17}$ According to Fattori et al., ${ }^{5}$ the degree of DE can be classified as mild, moderate, or severe based on radiologic imaging. The severity of this condition is suggested to be age related, which supports the theory that an ongoing pulsatile pressure of the cerebrospinal fluid on the lumbar and sacral canal causes progressive ballooning of a congenitally defective dural wall. ${ }^{18}$

The anesthetic literature on parturients with Marfan syndrome and confirmed DE is scarce. In three case reports, neuraxial technique was attempted but failed to produce a block adequate for surgical procedure, and in one case report with radiologically confirmed DE, epidural anesthesia was used successfully for elective Cesarean delivery (Table 2).
On the other hand, there are case reports where neuraxial anesthesia was used successfully in parturients with Marfan syndrome undergoing both Cesarean and vaginal delivery; however, diagnosis of DE was neither suspected clinically nor confirmed radiologically. ${ }^{19,20}$

The presence of DE may explain variability in the volume of cerebrospinal fluid, and as a result, different response to spinal anesthesia. Greater than normal volume of cerebrospinal fluid in the lumbar theca is postulated to restrict the spread of intrathecally injected local anesthetics and cause a "failed" spinal. ${ }^{21}$ Good correlations have been observed between the volume of lumbar CSF, measured by MRI, and the intrathecal spread of drugs in non-pregnant patients. ${ }^{22,23}$

Our patients exhibited different degrees of DE, and their dural sac dimensions at various lumbar levels are presented in Table 1. The anteroposterior dural sac diameters were measured perpendicular to the long axis of the dural sac at the midcorpus and lower endplate level of L1 through S1. Reference values were obtained from Oosterhof et al., where the authors measured dural sac dimensions in 44 healthy volunteers. ${ }^{15}$ Although, the difference in the dosing of spinal bupivacaine in our two cases makes the comparison between the effect difficult, in our view, the reason for a "failed" spinal in Case 1 was the greater severity of the patient's DE. Even a low dose of hyperbaric bupivacaine is expected to result in a T3-4 sensory block in healthy parturients. ${ }^{24}$

It is likely that the dimensions of the epidural space in patients with DE are also enlarged along with the dural sac. Despite the dural sac being a soft-tissue structure, it exerts sufficient pressure on the vertebra over time to cause bony changes of the spine. ${ }^{17}$ Therefore, an increased circumference of the bony canal may result in an enlarged epidural space, requiring a higher volume of local anesthetic to achieve sufficient levels, as was observed in Case 1. Further observations, however, are necessary to confirm this hypothesis. 
Table 2 Summary of published cases of neuraxial anesthesia for Cesarean delivery in parturients with Marfan syndrome and dural ectasia

\begin{tabular}{|c|c|c|}
\hline Reference & Anesthetic technique & Comments \\
\hline $\begin{array}{l}\text { Lacassie } \\
\text { et al. } \\
\quad\left(1^{\text {st }} \text { case }\right)\end{array}$ & $\begin{array}{l}\text { Continuous spinal catheter inserted at L4-5 interspace by midline } \\
\text { approach in left lateral position and left at } 4 \mathrm{~cm} \text { in the intrathecal } \\
\text { space. Incremental top up of the catheter with } 21 \mathrm{mg} \text { of } 0.5 \% \\
\text { bupivacaine. Highest sensory block T10. Aspiration of CSF was } \\
\text { confirmed at all times. }\end{array}$ & $\begin{array}{l}\text { Intrathecal catheter top up was stopped for fear of potential } \\
\text { neurologic injury. Fifty minutes later, the patient had a } \\
\text { T12 sensory block. General anesthesia was induced for } \\
\text { Cesarean delivery. A CT scan revealed ectatic dural sac. } \\
\text { Patient had a history of T1-L3 scoliosis repair. }\end{array}$ \\
\hline $\begin{array}{l}\text { Lacassie } \\
\quad \text { et al. } \\
\quad\left(2^{\text {nd }} \text { case }\right)\end{array}$ & $\begin{array}{l}\text { Spinal catheter inserted in left lateral position under CT fluoroscopic } \\
\text { guidance at L5-S1 level. The catheter was left at } 5 \mathrm{~cm} \text { in the } \\
\text { subarachnoid space. Patchy sensory block to T7 on the left and L1 } \\
\text { on the right after } 10 \mathrm{mg} \text { of incremental top up of } 0.5 \% \\
\text { bupivacaine and } 7.5 \mathrm{mg} \text { of } 0.75 \% \text { bupivacaine. Aspiration of CSF } \\
\text { was confirmed at all times. }\end{array}$ & $\begin{array}{l}\text { General anesthesia was induced due to the patchy block. The } \\
\text { images showed dural ectasia and severe kyphoscoliosis. } \\
\text { Spinal catheter was used for postoperative analgesia and } \\
\text { removed } 18 \mathrm{hr} \text { after delivery. On day } 3 \text {, patient } \\
\text { complained of most likely a postdural puncture headache } \\
\text { but refused the blood patch. The headache resolved on } \\
\text { postoperative day } 9 .\end{array}$ \\
\hline Tan et al. ${ }^{9}$ & $\begin{array}{l}\text { Epidural catheter inserted at L3-4 level and failed to produce an } \\
\text { adequate surgical block for Cesarean delivery after } 15 \mathrm{ml} \text { of } 2 \% \\
\text { lidocaine with epinephrine 1:200,000. Subarachnoid block at L3-4 } \\
\text { level with } 12 \mathrm{mg} \text { bupivacaine produced initial bilateral T4 block; } \\
\text { however, it was patchy } 10 \text { min into the procedure. }\end{array}$ & $\begin{array}{l}\text { General anesthesia was induced due to the patchy block. } \\
\text { Postpartum course was complicated with postdural } \\
\text { puncture headache. The authors reported constant "loss of } \\
\text { resistance" with increasing needle depth. No follow-up } \\
\text { imaging reported to confirm suspected diagnosis of dural } \\
\text { ectasia. }\end{array}$ \\
\hline Kim et al. $^{26}$ & $\begin{array}{l}\text { Epidural catheter was inserted at L3-4 interspace in lateral position. } \\
\text { A total dose of } 27 \mathrm{~mL} \text { of } 2 \% \text { lidocaine with epinephrine } \\
1: 200,000 \text { and } 100 \mu \mathrm{g} \text { of fentanyl was injected incrementally to } \\
\text { produce a T4 block bilaterally } 20 \text { min after injection. }\end{array}$ & $\begin{array}{l}\text { Uneventful Cesarean delivery. Epidural catheter was used } \\
\text { for postoperative analgesia for three days. }\end{array}$ \\
\hline
\end{tabular}

$\mathrm{CSF}=$ cerebrospinal fluid; $\mathrm{CT}=$ computed tomography

Although DE is not an absolute contraindication for epidural anesthesia, caution has been advised in its use for patients with Marfan syndrome and associated DE because of the theoretical risk of accidental dural puncture ${ }^{20}$ and CSF leak; however, when performed carefully by an experienced anesthesiologist, many benefits of epidural anesthesia, including minimal hemodynamic fluctuations and excellent postoperative pain control, can outweigh the potential risk. There has been some suggestion in the literature to perform an epidural in the lateral decubitus position to minimize the chance of accidental dural puncture. In this position, the ectatic dural sac is thought to be less extended in the region of needle insertion. ${ }^{20}$ We postulated that the lateral position may hinder the performance of the neuraxial technique and elected to perform the procedure with both patients in the sitting position. Although we did not acknowledge abnormal "loss of resistance" due to structural changes in the ligamentum flavum in either patient, this phenomenon has been suggested as a likely cause of accidental dural puncture. ${ }^{9}$

Patients with Marfan syndrome and associated scoliosis and DE pose many challenges to the anesthesiologist; therefore, we suggest a few details of our technique that could be useful to optimize the neuraxial technique and reduce the risk of complications. This assumption, however, requires confirmation in future observations. A pre-procedural ultrasound assessment of the spine may correctly identify the target interspace, determine the best interspace and insertion point in patients with scoliosis, and determine the depth to the epidural space; thus, it can potentially minimize the risk of a dural puncture. Electrical stimulation of the epidural catheter may be particularly useful in testing the catheter for double-segment CSEs and also in ascertaining the correct positioning of the catheter in patients with scoliosis. ${ }^{25}$

In summary, we reported two cases of parturients with Marfan syndrome and DE undergoing elective Cesarean delivery. Each patient responded differently to spinal anesthesia, most likely based on the severity of their DE. Although a preoperative MRI may help to identify patients at risk for a failed spinal, we suggest considering a CSE technique in cases of DE.

Conflict of interest None of the authors has a conflict of interest.

\section{References}

1. Judge DP, Dietz HC. Marfan's syndrome. Lancet 2005; 366: 1965-76.

2. Pyeritz $R$. Marfan syndrome and related disorders. In: Rimoin DL, Connor JM, Pyeritz RE, Korf BR, editors. Emery and Rimoin's Principles and Practice of Medical Genetics. 5th ed. London, UK: Churchill Livingstone; 2007. p. 3579-624.

3. Pyeritz RE, McKusick VA. The Marfan syndrome: diagnosis and management. N Engl J Med 1979; 300: 772-7.

4. De Paepe A, Devereux RB, Dietz HC, Hennekam RC, Pyeritz RE. Revised diagnostic criteria for the Marfan syndrome. Am J Med Genet 1996; 62: 417-26.

5. Fattori R, Nienaber CA, Descovich B, et al. Importance of dural ectasia in phenotypic assessment of Marfan's syndrome. Lancet 1999; 354: 910-3. 
6. Lundby R, Rand-Hendriksen S, Hald KJ, et al. Dural ectasia in Marfan syndrome: a case control study. AJNR Am J Neuroradiol 2009; 30: 1534-40.

7. Foran JR, Pyeritz RE, Dietz HC, Sponseller PD. Characterization of symptoms associated with dural ectasia in the Marfan patients. Am J Med Genet A 2005; 134A: 58-65.

8. Lacassie HJ, Millar S, Leithe LG, et al. Dural ectasia: a likely cause of inadequate spinal anaesthesia in two parturients with Marfan's syndrome. Br J Anaesth 2005; 94: 500-4.

9. Tan A, Kaul B, Vallejo MC, DeRenzo J, Waters J. Anesthetic management of cesarean section in a parturient with Marfan's syndrome and critical aortic dilation. Anesthesiology 2007; 106(Suppl 1): A-244. (abstract).

10. Tsui BC, Gupta S, Finucane B. Confirmation of epidural catheter placement using nerve stimulation. Can J Anaesth 1998; 45: 640-4.

11. Stern WE. Dural ectasia and the Marfan syndrome. J Neurosurg 1988; 69: 221-7.

12. Casselman ES, Mandell GA. Vertebral scalloping in neurofibromatosis. Radiology 1979; 131: 89-94.

13. Abello R, Rovira M, Sanz MP, et al. MRI and CT of ankylosing spondylitis with vertebral scalloping. Neuroradiology 1988; 30: 272-5.

14. Schwend RM, Hennrikus W, Hall JE, Emans JB. Childhood scoliosis: clinical indications for magnetic resonance imaging. J Bone Joint Surg Am 1995; 77: 46-53.

15. Oosterhof T, Groenink M, Hulsmans FJ, et al. Quantitative assessment of dural ectasia as a marker for Marfan syndrome. Radiology 2001; 220: 514-8.

16. Ahn NU, Sponseller PD, Ahn UM, et al. Dural ectasia in the Marfan syndrome: MR and CT findings and criteria. Genet Med 2000; 2: 173-9.

17. Sponseller PD, Ahn NU, Ahn UM, et al. Osseous anatomy of the lambosacral spine in Marfan syndrome. Spine (Phila Pa 1976) 2000; 25: 2797-802.
18. Pyeritz RE, Fishman EK, Bernhardt BA, Siegelman SS. Dural ectasia is a common feature of the Marfan syndrome. Am J Hum Genet 1988; 43: 726-32.

19. Buser RJ, Mordecai MM, Brull SJ. Combined spinal-epidural analgesia for labor in a patient with Marfan's syndrome. Int J Obstet Anesth 2007; 16: 274-6.

20. Jayaram A, Carp HM, Davis L, Jacobson SL. Pregnancy complicated by aortic dissection: caesarean delivery during extradural anaesthesia. Br J Anaesth 1995; 75: 358-60.

21. Fettes PD, Jansson JR, Wildsmith JA. Failed spinal anaesthesia: mechanisms, management, and prevention. Br J Anaesth 2009; 102: 739-48.

22. Carpenter RL, Hogan QH, Liu SS, Crane B, Moore J. Lumbosacral cerebrospinal fluid volume is the primary determinant of sensory block extent and duration during spinal anesthesia. Anesthesiology 1998; 89: 24-9.

23. Higuchi H, Hirata J, Adachi Y, Kazama T. Influence of lumbosacral cerebrospinal fluid density, velocity and volume on extent and duration of plain bupivacaine spinal anesthesia. Anesthesiology 2004; 100: 106-14.

24. Van de Velde M, Van Schoubroeck D, Jani J, Teunkens A, Missant $C$, Deprest $J$. Combined spinal epidural anesthesia for cesarean delivery: dose-dependent effects of hyperbaric bupivacaine on maternal hemodynamics. Anesth Analg 2006; 103: 187-90.

25. Carvalho JC. Ultrasound-facilitated epidurals and spinals in obstetrics. Anesthesiol Clin 2008; 26: 145-58.

26. Kim G, Ko JS, Choi DH. Epidural anesthesia for cesarean section in a patient with Marfan syndrome and dural ectasia - a case report. Korean J Anesthesiol 2011; 60: 214-6. 